\title{
МОДЕЛИ ОБРАЗОВАНИЯ СУЩЕСТВИТЕЛЬНЫХ СУФФИКСАЛЬНОГО ТИПА В НЕМЕЦКОМ ЯЗЫКЕ
}

\section{MODELS OF FORMATION OF NONS OF SUFFIXAL TYPE IN GERMAN}

V. Panfilova

L. Yushkova

Summary: The article presents the results of the analysis of derivational models of nouns of the suffix type in modern German, in particular, the models of nouns of the de-objective type with both native German suffixes and foreign-language suffixes were identified and analyzed. Also, a content analysis of research on the problem of allocation of derivational meaning in a derived word was carried out. The article provides a classification of models of suffixal nouns depending on the derivational meaning, as well as distinctive features and characteristics of each specific category. The authors have identified the most productive model of word formation.

Keywords: derivational model, noun, suffix type, German.

\author{
Панфилова Валентина Михайловна \\ К.n.н., доцент, Казанский федеральный университет \\ valova55v@yandex.ru \\ Юикова Людмила Анатольевна \\ Д.филол.н., доцент, Удмуртский государственный \\ университет иностранных языков в срере права, \\ экономики и управления \\ jushkova1@yandex.ru
}

Аннотация: В статье приводятся результаты выполненного анализа словообразовательных моделей имен существительных суффиксального типа в современном немецком языке, в частности были выявлены и проанализированы модели существительных деадеъективного типа как с исконно немецкими суффиксами, так и с иностранноязычными суффиксами. Также был проведен контент-анализ исследований проблемы выделения в производном слове словообразовательного значения. В статье приводится классификация моделей суффиксальных существительных в зависимости от словообразовательного значения, а также отличительные особенности и характеристики каждой конкретной категории. Авторами определена наиболее продуктивная модель образования слов.

Ключевые слова: словообразовательная модель, имя существительное, суффиксальный тип, немецкий язык.

именуют «словообразовательным типом». Эти понятия имеют несколько определений согласно различным подходам:

1. Словообразовательные модель и тип иерархически зависят друг от друга. Здесь важно отметить, что позиции лингвистов относительно родства этих понятий различаются.

Первая группа исследователей придерживается позиции, что термин «словообразовательная модель» и «словообразовательный тип» являются родственными. В.Н. Немченко отмечает, что под первым понятием необходимо подразумевать общую формулу или схему для построения производных слов, которая определяет структуру этих производных слов или используется в качестве образца для образования новых лексических единиц. При этом, давая определение модели образования слов, необходимо брать во внимание внешние признаки, которые являются формальными при моделировании производных слов, они обозначают принадлежность к той или части речи и имеют определенные форманты.

При позиционировании и определении «словообразовательного типа» необходимо учитывать ряд конкретных характеристик и параметров производных. К ним относятся: 
1. Производящие слова имеют лексикограмматический характер, то есть они принадлежат к определенным частям речи.

2. Присутствие формантов или специфичных словообразовательных средств.

3. Семантическое отношение производных к производящим с сохранением и определением словообразовательного значения [2].

Другая группа исследователей придерживается позиции, согласно которой понятие «типа» по отношению к понятию «модели» представляет собой гипероним. При этом Е.А. Земской отмечает, что под «словообразовательным типом» необходимо понимать схему или формулу для образования производных, которая соответствует общности следующих трех элементов:

1. Та же часть речь, что и у основы, от которой она происходит.

2. Отношения между производящими и производными выстраиваются по следующему типу: общность способа образования.

3. При использовании аффиксных методов присутствует тождественность аффикса.

При этом исследователь отмечает, что понятие «модели» необходимо использовать для позиционирования морфологических видов внутри того или иного словообразовательного типа.

2. Второй подход заключается в том, что понятия словообразовательных моделей и типов использовались как синонимы. К примеру, В. Флейшер считает, что под моделью необходимо понимать схемы, структурные типы и образцы, на основании которых образуются или могут в последующем образовываться слова, принадлежащие к различным частям речи [3].

3. Ряд ученых позиционирует понятие «словообразовательного типа» как способ словообразования, при этом полностью игнорируют присутствие и возможность применения понятия «модель» [4].

4. Ряд работ современных немецких лингвистов не содержит обоих рассматриваемых терминов, что говорит о том, что ряд немецких лингвистов отказались от данных терминов и используют другие категории $[5,6]$. К примеру, А. Мотч использует категорию «словообразовательного образца», который подразумевает под собой специализированный образец для осуществления анализа комплексных языковых символов и характерных для них содержательных и звуковых признаков.

Если говорить о современной германистике, то в ней большее распространение получил термин «словообразовательная модель», поэтому в данной работе преимущественно будет использоваться он. В процессе модельного определения необходимо выявить характер отношений между смыслами и значениями основ, как мотивирующих, так и мотивированных.

На сегодняшний день в теории словообразования немецкого языка нельзя выделить конкретное решение относительно определения носителя значения для образования слов. Группа ученых придерживается мнения, что значения данного типа имеют советующий формант $[7,8]$. Другая группа исследователей придерживается позиции, что значение для образования слов представляет собой сложно структурированное значение, которое позиционирует и определяет конкретный вид отношений между ролевыми структурами компонентов производного слова. Это отношения, которые выявляют и демонстрируют один компонент как основу, а другой как его характеристику или признак, при этом второй компонент выполняет роль мотивирующей части $[9,10]$.

Поэтому сегодня, говоря о значении образования слов, мы понимаем тип отношений, который складывается между мотивирующими и мотивированными основами. Современные словообразовательные модели имен существительных суффиксального типа немецкого языка определяются, исходя их наличия форманта, как исконного немецкого, так и заимствованного из иностранных языков $[11,12]$.

\section{Основная часть}

Цель исследования заключалась в анализе особенностей словообразовательных суффиксов имен существительных в современном немецком языке, а также в определении и представлении основных моделей словообразования.

Предмет исследования включал в себя современные немецкие суффиксы, используемые в немецкоязычной сфере. Изучение механизмов образования существительных в немецком языке является актуальным вопросом и представляет интерес для более глубокого изучения, поскольку многие аспекты этой темы остаются спорными. Это объясняется тем, что современный язык реагирует на новые социальные, технологические, научные тенденции, он пополняется соответствующей лексикой и развивается, что стимулирует возникновение специфичных вопросов.

В рамках исследования использовались такие методы как контент-анализ, литературный обзор, метод непрерывной выборки материала, сравнительно-сравнительный метод, методы компонентного и структурносемантического анализа.

На основании значения образования слов словообразовательные модели имен существительных суффик- 
сального типа в современном немецком языке можно разделить на следующие категории (название каждой категории соответствует словообразовательному значению):

1. Непроцессуальный признак, который относится к субстантивному типу и именуется мотивирующим именем прилагательным. Производные этой группы означают субстантивные параметры. В данном случае используются следующие модели: «A + -anz/-heit/ -tät или -ität/ -keit/-igkeit/-e/». В качестве примеров можно привести следующие существительные: «Naivität», «Sanftheit», «Breite».

К данной категории также относятся следующие модели: «A + -nis/- ion или -ation/-schaft/-ik/- tum/-ie/-esse/erie». Однако данные модели используются реже.

В ряде имен существительных, имеющих значение субстантивного признака, в качестве вторичного значения используются «носители признака». В первой категории необходимо выделить следующие группы:

1.1. Носителем признака является предмет, выражение, явление, слово или поступок. Примерами являются модели «A + -heit /- keit/-tum», это можно проследить в следующих образцах: «Heiligtum», «Grobheit», «Höflichkeit».

1.2. Носителем признака является пространство или место. Здесь используются модели «А + -e/ -heit / ikum. Примерами являются следующие выражения: «Baltikum», «Höhe», «Leerheit».

1.3.B) Носителем признака являются однородные предметы. Сюда входят такие непродуктивные модели как «A + -schaft/-tum/ikikum», что отражается в примерах: «Antibiotikum», «Gemeinschaft», «Elektronik».

1.4. Носителем признака является вещество. Это модели «A + -keit/-e»: «Säure», «Flüssigkeit».

1.5. Носителем языка является конкретное лицо. В данном случае активными являются следующие модели: «A + -heit/- keit/-schaft/-ät». В качестве примеров можно привести следующие лексические единицы: «Bekanntschaft», «Individualität», «Berühmtheit».

2. Состояние или поведение лица, которое характеризуется мотивирующим прилагательным. Данной категории свойственны следующие модели: «A + -heit/keit/-igkeit/-schaft/-tum/-erie/-esse/-ik/-ismus». Примерами употребления данных моделей являются следующие слова: «Patriotismus», «Zufriedenheit», «Bigotterie», «Appetitlosigkeit», «Schwangerschaft», «Akkuratesse».
3. Признак в качестве общественного, идейного, политического, эстетического или научного вектора, который выражает склонность в том или ином направлении и образ мыслей. В данной категории активными являются следующие модели: «A + -ismus или -asmus/-ik». Примеры употребления модели: «Ästhetik», «Katholizismus», «Ethik».

4. Носителем признака выступает лицо, которое является мотивирующим прилагательным. В этой ситуации применяются продуктивные модели «A + -ling/-chen/-i/ iker/ist» и непродуктивные модели «A + -er/-ian или -jan». К четвертой категории также можно отнести следующие модели, эксплуатирующиеся для образования производных: «A + -ling/-i». Примерами являются «Dummi», «Feigling», «Liedrjan». Особого внимания при рассмотрении данной категории заслуживает модель «A + -chen», так как ее можно охарактеризовать мелиоративной коннотацией. Примерами данной модели являются «Kleinchen», «Dummchen» и так далее.

5. Нейральные модели со стилистической точки зрения. Это производные, построенные на основании следующей схемы: «A + iker/+ ist»: «Zivilist», «Optimist» и так далее.

6. Носителем признака является неодушевленный пример. Сюда относятся такие модели как «А + -tum/ling/-anz/-ät/-on». Например: «Lexikon», «Heiligtum», «Antiquität» и так далее.

\section{Выво $\Delta ы$}

На основании проведенного комплексного анализа можно сделать вывод о том, что в современном немецком языке присутствует большой массив моделей, служащих для образования слов, которые имеют как заимствованные форманты иноязычного происхождения, так и форманты, характерные для исконного немецкого языка. При этом необходимо выделить наиболее продуктивны и наиболее распространенные модели:

1. «A+-(it)ät».

2. «A+-heit».

3. «A+-(ig)keit».

Если говорить о словообразовании немецкого языка в целом, то нужно отметить особое положение имен существительных. Они обладают широкой функциональностью и могут сочетаться с остальными частями речи, образуя новые слова. Наиболее продуктивным методом сегодня является суффиксальный, что объясняется большое количество имен существительных суффиксального типа.

\section{ЛИТЕРАТУРА}

1. Виноградова В.Н. Стилистические средства словообразования / В.Д. Левин // Стилистические исследования (на материале современного русского языка). М.: Наука, 1972. С. 175-317. 
2. Немченко В.Н. Современный русский язык: Морфемика и словообразование. - Н. Новгород: Нижегород. гос. ун-т им. Н.И. Лобачевского, 1994. - 295 с.

3. Fleischer W. Wortbildung der deutschen Gegenwartssprache. - Leipzig: VEB Bibliografisches Institut, 1969. - $326 \mathrm{~S}$.

4. Vogel P.M. Wortarten und Wortartenwechsel: Zu Konversion und verwandten Erscheinungen im Deutschen und in anderen Sprachen. - Berlin, New York: de Gruyter, 1996. -317 S.

5. Motsch W. Deutsche Wortbildung in Grundzügen. - Berlin, New York: de Gruyter, 2004. - 458 S.

6. Zhou Mei, Tompa Frank Wm. The suffix-signature method for searching for phrases in text // Information Systems, Volume 23, Issue 8, December 1998. - pp. 567-588

7. Улуханов И.С. Словообразовательная семантика в русском языке и принципы ее описания. - М.: Наука, 1977. - 256 с

8. Зуев А.Н., Молчанова И.Д., Мурясов Р.З. Словарь словообразовательных элементов немецкого языка. М.: Рус. яз., 1979.

9. Кубрякова Е.С. Типы языковых значений. Семантика производного слова. - М.: Наука, 1987. - 200 с.

10. Архипова И.В. Высказывание с предложными девербативами в современном немецком языке // Вестник Новосибирского государственного педагогического университета-2012.- №5.-С.95-104.

11. Duden. Die Grammatik (Bd. 4) [Text]. 8., überarbeitete Aufl. - Mannheim; Leipzig; Wien; Zürich: Dudenverlag, 2009. - 1343 S.

12. Р.3. Словообразование и функционально-семантические категории (на материале суффиксальных существительных немецкого языка) [Текст] / Р.3. Мурясов. - Уфа: БашГУ, 1993. - 224 с.

( П Панфилова Валентина Михайловна (valova55v@yandex.ru), Юшкова Людмила Анатольевна (jushkova1@yandex.ru).

Журнал «Современная наука: актуальные проблемы теории и практики»

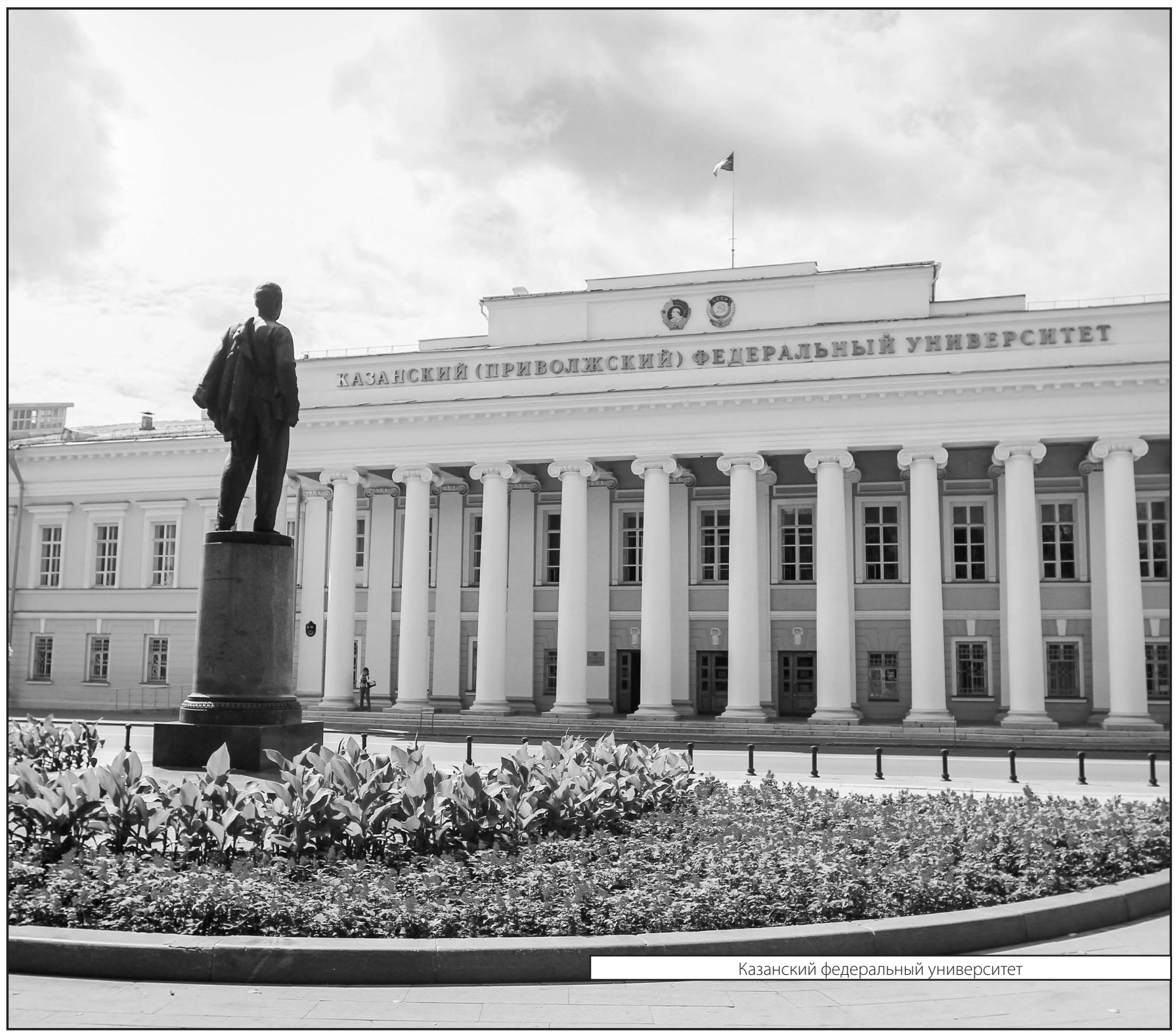

